\title{
Birleştirilmiş Sınıflı İlkokullardaki Uygulamaların Sınıf Öğretmenliği Lisans Programı Öğrencilerinin Öğretmenlik Tutumuna Etkisinin İncelenmesi
}

\author{
Özgür Babayiğit \\ Yozgat Bozok Üniversitesi, Eğitim Fakültesi, Temel Eğitim Bölümü, Yozgat \\ ozgur.babayigit@bozok.edu.tr \\ ORCID ID: http://orcid.org/0000-0001-6123-0609
}

\begin{tabular}{|c|c|c|}
\hline \multicolumn{3}{|c|}{ Araştırma Makalesi } \\
\hline Geliş Tarihi: 17.01.2019 & Revize Tarihi: 07.05.2019 & Kabul Tarihi: 07.05.2019 \\
\hline
\end{tabular}

Dergisi, 5(1),43-53.

\section{ÖZ}

$\mathrm{Bu}$ araştırmanın amacı, birleştirilmiş sınıflarda öğretim dersi kapsamında, birleştirilmiş sınıflı ilkokullardaki uygulamaların, sınıf öğretmenliği lisans programı dördüncü sınıf öğrencilerinin öğretmenlik tutumuna etkisinin incelenmesidir. Araştırma tek grup öntest-sontest deneysel desendedir. Araştırmanın evrenini Yozgat Bozok Üniversitesi Eğitim Fakültesi Sınıf Öğretmenliği programında öğrenim görmekte olan dördüncü sınıf öğrencileri oluşturmaktadır. Birleştirilmiş sınıflarda öğretim dersini alan 27 öğrenci bulunmaktadır. Veri toplama aracı olarak öğretmenliğe ilişkin tutum ölçeği kullanılmıştır. Araştırma 2017 y1lı şubat ve mart aylarında gerçekleştirilmiştir. Araştırma kapsamında Yozgat'ta bulunan birleştirilmiş sınıflı ilkokullarda dört haftalık süre ile uygulama yapılmıștır. Birleștirilmiş sınıflarda öğretim dersini alan sınıf öğretmenliği programı dördüncü sınıf öğrencileriyle deneysel işlem gerçekleştirilmiştir. Araştırmacı tarafından hazırlanan plan kapsamında, öğrenciler tarafından, birleştirilmiş sınıflarda ders etkinlikleri ve uygulamalar gerçekleştirilmiştir. Verilerin analizinde ilişkili örneklemler için $t$ testi uygulanmıştır. Araştırma sonucunda öğretmenliğe ilişkin tutum ölçeği öntest puanları ile sontest puanları arasında anlamlı bir farklılık olmadığı belirlenmiştir, $\mathrm{t}_{(26)}=1,48$, $\mathrm{p}>, 05$. Öğrencilerin öğretmenliğe ilişkin tutum ölçeği öntest puan ortalamaları $(\bar{x}=4,20)$ ve sontest puan ortalamaları $(\bar{x}=4,37)$ incelendiğinde, sınıf eğitimi anabilim dalı son sınıf öğrencilerinin öğretmenliğe ilişkin olumlu yüksek derecede tutum sahibi oldukları tespit edilmiştir. Öğretmenliğe ilişkin tutum ölçeği öntest puanları ile öğretmenliğe ilişkin tutum ölçeği sontest puanları arasında anlamlı bir fark olmamasına rağmen, ögretmenlik tutumunda az da olsa katkı sağladığı görülmektedir.

Anahtar Kelimeler: Birleştirilmiş sınıf, ilkokul, sınıf, tutum, uygulama.

\section{Investigation of the Effects of Primary School Teacher Program Students on Teaching Attitudes of Practices in Multigrade School}

\begin{abstract}
The aim of this study is to investigate the effects of the applications in the multigrade class primary schools on the teaching attitude of the fourth year students of the classroom teacher program in the multigrade classrooms. The only group of research is pretest-posttest experimental design. The population of the study is composed of the fourth grade students studying in the Yozgat Bozok University Faculty of Education. There are 27 students in the multigrade classrooms. Attitude scale related to teaching was used as data collection tool. The research was conducted in February and March 2017. In the scope of the research, a four-week period was applied in the unified class primary schools in Yozgat. Experimental procedure was carried out with fourth grade students in the classroom teaching program that took the teaching class in the multigrade classes. Within the scope of the plan prepared by the researcher, lesson activities and practices were realized by the students in the multigrade classes. In the analysis of the data, $t$ test was applied for the related samples. At the end of the study, it was determined that there was no significant difference between the pre-test and post-test scores of the attitude scale related to teaching, $\mathrm{t}_{(26)}=1,48, \mathrm{p}>.05$. When the mean scores of the attitude scale $(\bar{x}=4.20)$ and posttest mean scores $(\bar{x}=4.37)$ of the students were examined, it was determined that the students of the senior education department had a positive attitude towards teaching. Although there was no significant difference between the pre-test scores of the attitude scale and the posttest scores of the teaching attitude scale, it was observed that it contributed a little to the teaching attitude.
\end{abstract}

Keywords: Multigrade class, elementary school, practice, attitude.

\section{Giriş}

Birleştirilmiş sınıf, ülkemiz gerçeklerinden biridir. Öğrenci sayısının azlığı, öğretmen sayısının yetersizliği, derslik sayısının yetersizliği veya yerleşim birimlerinin dağılımı gibi nedenlerle 
birleştirilmiş sınıf uygulamasına başvurulmaktadır. Birleştirilmiş sınıf, öğrenci açısından bir dezavantaj olarak görülse de, ögrencilerin zorunlu olan ilkokul öğrenimini almaları bakımından önemlidir.

Birleştirilmiş sınıf, bir öğretmenin sorumluluğunda, farklı yaş gruplarındaki iki veya daha fazla sinıfin aynı zaman diliminde bir araya getirilmesidir (Little, 2006; Hargreaves, Montero, Chau, Sibli ve Thanh, 2001; Berry, 2001; Birch ve Lally, 1995; Thomas ve Shaw, 1992). Bir başka tanımla; bir okulda, birden fazla sınıfin birleştirilmesiyle bir grup oluşturulmasına birleştirilmiş sınıf denilmektedir (Gültekin, 2012; Erdem, 2015). Birleştirilmiş sınıflarda öğretim uygulaması dünyanın farklı ülkelerinde uygulanmaktadır (İzci, Duran ve Taşar, 2010). Türkiye'de geçmişte öğretmenlerin ve dersliklerin sayısının yetersizliği, mevcut durumda ise öğrenci sayısının azlığı gibi sebeplerle özellikle köy ilkokullarında birleştirilmiş sınıflarda öğretim gerçekleştirilmektedir (Dursun, 2006). Türkiye'de, nüfusu az olan yerleşim birimlerinde ilkokuldaki öğrenci sayısı az olduğundan her sınıfin çok az öğrenci mevcudu olmaktadır. Öğrenci sayısının çok az olduğu bu yerleşim birimlerinde dört derslikli okulların yapılması ve her seviyedeki sınıfa öğretmen görevlendirilmesi olanaklı ve ekonomik olmamaktadır (Gültekin, 2012; Taşdemir, 2014).

Okulda öğrencileri sınıflara ayırma fikri, 1800'lü yıllara kadar dayanmaktadır (Thomas ve Shaw, 1992). Sınıf, okulda ve öğretim kurumunda hızlı bir biçimde düzenleme birimi haline gelmiştir. Sınıf düzeyi ağırlıklı olarak öğrenci yaşına göre belirlenmektedir. Bir sınıf, aynı yaştaki çocuklardan oluşmaktadır. Bu sınıflara bağımsız sınıf denilmektedir (Gültekin, 2012).

Türkiye'de birleştirilmiş sınıflarda öğretim, tüm öğrencilerin zorunlu olan ilkokul eğitiminden yararlanması amacına hizmet eden bir eğitim gerçeğidir. Birleştirilmiş sınıflarda öğretim özellikle köy olgusuna dayanmaktadır (Gültekin, 2012; Mulryan-Kyne, 2007). Birleştirilmiş sınıflarda öğretimin ortaya çıkmasına birbiriyle ilişkili üç sebep oluşturmaktadır. Bu sebepler şunlardır: (Erdem, 2015; Gültekin, 2012):

1. Öğrenci sayısının az olması.

2. Öğretmen sayısının yetersiz olması.

3. Derslik sayısının az olması.

Birleştirilmiş sınıf, ülkemizde uygulandığı gibi diğer dünya ülkelerinde de uygulanmaktadır. Bugün Avrupa Birliği ülkelerinin neredeyse tamamında, Amerika Birleşik Devletleri, Japonya ve Kanada gibi pek çok ülkede birleştirilmiş sınıf uygulaması bulunmaktadır (MEB, 2012). Resim 1, Resim 2, Resim 3 ve Resim 4 'te farklı ülkelerdeki birleştirilmişs sınıf uygulamaları görülmektedir.

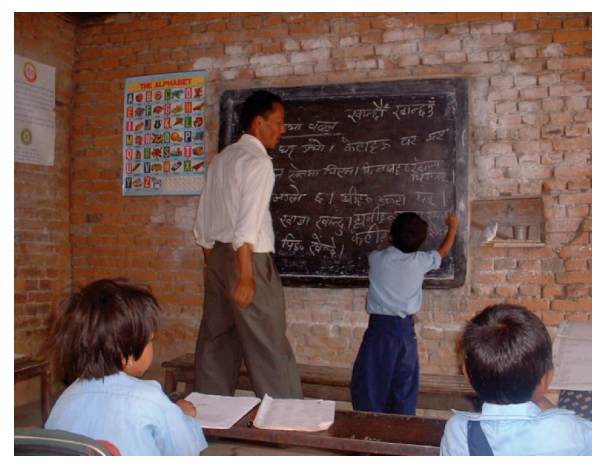

Resim 1. Nepal'de Birleştirilmiş Sınıf (Little, 2006, s. 351). 


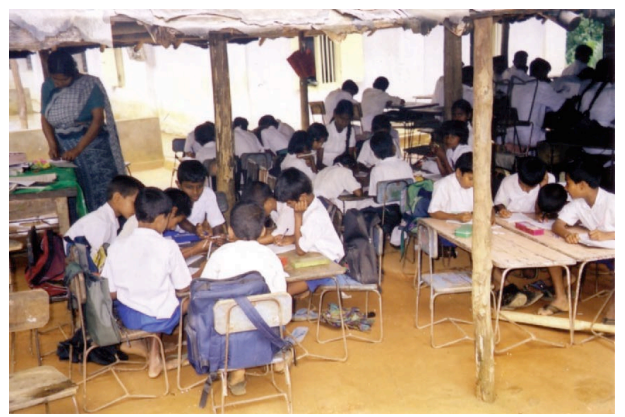

Resim 2. Sri Lanka'da Birleştirilmiş Sınıf (Little, 2006, s. 354)

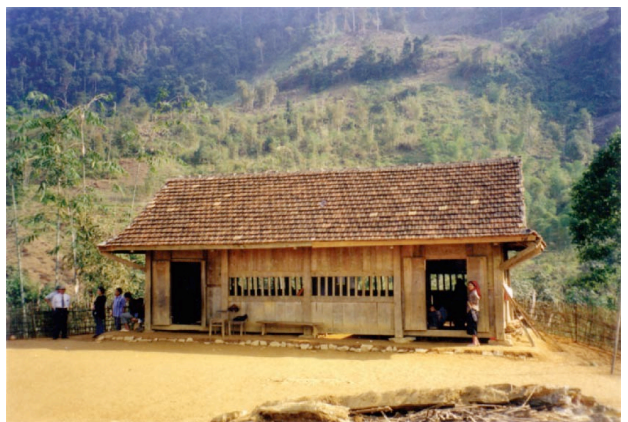

Resim 3. Vietnam'da Birleştirilmiş Okul (Little, 2006, s. 356)

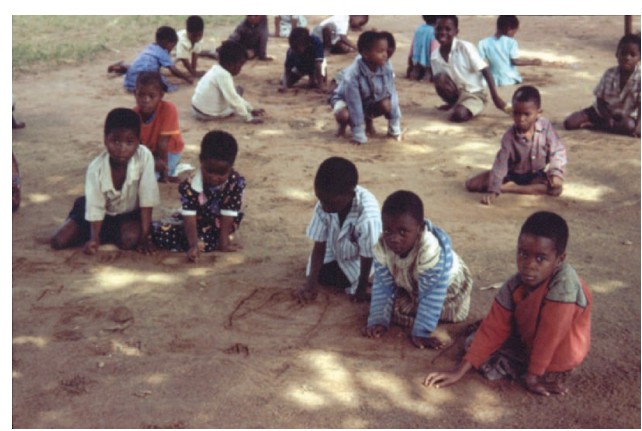

Resim 4. Malawi'de Birleştirilmiş Sınıf (Little, 2006, s. 352)

Türkiye'de ise nüfus dağılımı, birleştirilmişs sınıf uygulamasını zorunlu hale getirmektedir. Ülkemizin tüm illerinde birleştirilmiş sınıf uygulamasının yapıldığ 1 okullar mevcuttur. Milli Eğitim Bakanlığının 2011-2012 eğitim-öğretim yılı verilerine göre; 10.413 ilköğretim okulundaki 305.201 öğrenci birleştirilmiş sınıflarda eğitim görmektedir. Türkiye'deki ilköğretim okullarının $\% 35^{\prime} \mathrm{i}$ birleştirilmiş sınıf içeren okullardır (MEB, 2012). Yükseköğretim Kurulu Başkanlığı (2006) sınıf öğretmenliğ̣i lisans programı ders tablosuna göre, birleştirilmiş sınıflarda öğretim dersi iki saat teorik bir derstir. Uygulamas1 yoktur.

Konu ile ilgili olarak Mulryan-Kyne, (2007); İzci, Duran, Taşar (2010); Sağ (2011); Yıldız ve Köksal (2009); İnce ve Şahin (2016); Eker ve Sıcak (2016); Taşdemir (2016); Sağ, Savaş ve Sezer (2009); İzci (2008); İlter (2015); Kazu ve Aslan (2016); Sağ (2010) tarafindan çeşitli araştırmalar yapılmıştır. Yapılan ilgili araştırmalar incelendiğinde, ağırlıklı olarak birleştirilmiş sınıflarda öğretim dersini alan ögrencilerin görüşlerine başvurulduğu anlaşılmaktadır. Bunun yanı sıra, birleştirilmiş sınıfta öğrenim gören öğrencilerin başarı, tutum gibi özelliklerinin sıklıkla çalışıldığı görülmektedir. Ancak birleştirilmiş sınıflarla ilgili, sınıf öğretmenliği programı öğrencileri ile yapılan uygulamalı çalışma sayısı oldukça sınırlıdır.

$\mathrm{Bu}$ araştırmanın amacı, birleştirilmiş sınıflarda öğretim dersi kapsamında, birleştirilmiş sınıflı ilkokullardaki uygulamaların, sınıf öğretmenliği lisans programı dördüncü sınıf öğrencilerinin öğretmenlik tutumuna etkisinin incelenmesidir. Yükseköğretim Kurulu Başkanlığı (2006) sınıf öğretmenliği lisans programı ders tablosuna göre, birleştirilmiş sınıflarda öğretim dersi iki saat teorik 
bir derstir. Uygulaması yoktur. Yükseköğretim Kurulu Başkanlığı tarafindan 2018 y1lında yürürlüğe konulan sınıf öğretmenliği lisans programında ise birleştirilmiş sınıflarda öğretim dersi bulunmamaktadır. Yapılan bu araştırma ile birleştirilmiş sınıflarda öğretim dersine uygulama boyutu eklenmiştir. $\mathrm{Bu}$ uygulamanın etkisinin incelenmesi açısından önemlidir. Araştırma sonuçlarının Yükseköğretim Kurulu Başkanlığında öğretmenlik lisans programlarını hazırlayan komisyona faydalı olacağı düşünülmektedir. Bunun yanı sıra, birleştirilmiş sınıf alanında çalışan araştırmacılara fikir vereceği düşünülmektedir.

\section{Yöntem}

\section{Araştırma Modeli}

Birleştirilmiş sınıflı ilkokullardaki uygulamaların sınıf öğretmenliği programı öğrencilerinin öğretmenlik tutumuna etkisinin incelendiği bu araştırma tek grup öntest-sontest deneysel desendedir. Tek grup öntest-sontest deneysel desende bütün katılımcilar var olan tek gruba atandıktan sonra öntest uygulanmaktadır. Takip eden aşamada deneysel uygulama gerçekleştirilmektedir. Araştırmanın son safhasında sontest uygulanmakta ve sonuçlar kayıt altına alınmaktadır (Gliner, Morgan ve Leech, 2015). Öntest ile sontest puanları arasındaki fark, müdahalenin ne kadar etkili olduğunu göstermektedir (Christensen, Johnson ve Turner, 2015). Modelin simgesel gösterimi Şekil 1'deki gibidir (Karasar, 1994):

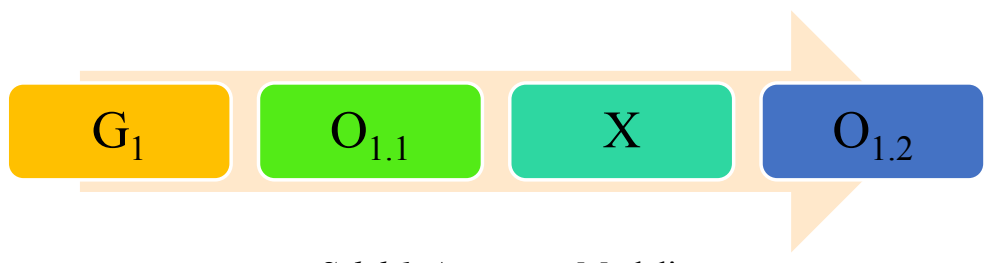

Şekil 1. Araştırma Modeli

Şekil 1'deki araştırma modelinde $\mathrm{O}_{1.2}>\mathrm{O}_{1.1}$ olması halinin " $\mathrm{X}$ " den dolayı olduğu kabul edilmektedir (Karasar, 1994).

\section{Evren ve Örneklem}

Araştırmanın evrenini Yozgat Bozok Üniversitesi Eğitim Fakültesi Sınıf Öğretmenliği programında öğrenim görmekte olan dördüncü sınıf öğrencileri oluşturmaktadır. Örneklem alınmamış, evrenin tamamına ulaşılmıştır. Evren ve örneklemin belirlemesinde amaçlı örnekleme yöntemlerinden kolay ulaşılabilir durum örneklemesi ve ölçüt örnekleme kullanılmıştır. Kolay ulaşılabilir durum örnekleme yöntemi araştırmaya hız ve pratiklik kazandırır (Yıldırım ve Şimşek, 2006; Patton, 2014). Ölçüt örnekleme önceden belirlenmiş bazı önem ölçütlerini karşılayan tüm durumları çalışma ve gözden geçirmektir (Patton, 2014). Burada sözü edilen ölçüt veya ölçütler araştırmacı tarafından oluşturulabilir ya da önceden hazırlanmıș bir ölçüt listesi kullanılabilir (Yıldırım ve Şimșek, 2006). Ölçüt olarak, Birleştirilmiş Sınıflarda Öğretim dersini alan öğrenciler belirlenmişsir. Birleştirilmiş Sınıflarda Öğretim dersini alan 27 öğrenci bulunmaktadır. Bu öğrencilerin 8'i erkek 19’u kız öğrencidir.

\section{Veri Toplama Aracı}

Veri toplama aracı olarak Erkuş, Sanlı, Bağlı ve Güven (2000) tarafından geliştirilen “Öğretmenliğe İlişkin Tutum Ölçeği” kullanılmıştır. Ölçek kullanımı için izin alınmıştır. Ölçek 23 maddeden oluşmaktadır. 5'li likert tiptedir. Beş dereceli ölçekte ise en çok 115 puan alınabilir. Her iki ölçekten de alınabilecek en düşük puan 23 'tür. Bu haliyle ölçeklerden alınan toplam puanlar, madde sayısına (23) bölünerek, bireylerin elde ettikleri ortalama madde puanlarına göre, bireylerin öğretmenliğe ilişkin tutumları hakkında bir yargıya varılabilmektedir.

\section{Deneysel Süreç}


Araştırma 2017 yılı şubat ve mart aylarında gerçekleştirilmiştir. Araştırma kapsamında Yozgat'ta bulunan birleştirilmiş sınıflı ilkokullarda dört haftalık süre ile uygulama yapılmıştır. 20162017 eğitim-öğretim y1lı bahar yarıyılında birleştirilmiş sınıflarda öğretim dersini alan sınıf öğretmenliği programı dördüncü sınıf öğrencileriyle deneysel işlem gerçekleştirilmiş̧ir. Araştırmacı tarafından hazırlanan plan kapsamında, öğrenciler tarafından, birleştirilmiş sınıflarda ders etkinlikleri ve uygulamalar gerçekleştirilmiştir. Bu uygulamalarda sınıf öğretmeni süreci gözlemlemiştir. Gerekli yerlerde sınıf öğretmeni tarafından düzeltme ve katkılar yapılmıştır. Öğretmenli dersler ile birlikte ödevli derslerin sorumluluğu sınıf öğretmeni adayında olmuştur. Araştırmacı, deneysel süreçte sınıf öğretmenliği programı dördüncü sınıf öğrencilerine danışmanlık hizmeti vermiştir. Ders planlarında yer alan kazanımlar çerçevesinde dersler yürütülmüştür. Bu planlarda ders kapsamında yürütülecek olan uygulamalr ve etkinlikler yer almaktadır.

\section{Verilerin Analizi}

Verilerin analizinde SPSS programı kullanılmıştır. Öğrencilerin "Öğretmenliğe İlişkin Tutum Ölçeği”ne belirtmiş oldukları işaretlemeler SPSS programına girilmiştir. Verilerin normal dağılımına grubun 50 kişiden az olması nedeniyle Shapiro-Wilks testi ile bakılmıştır (Büyüköztürk, 2012). Yapılan Shapiro-Wilks testi sonucunda $\mathrm{p}=, 16$ bulunmuştur. Verilerin normal dağılım gösterdiği belirlendikten sonra, ilişkili örneklemler için $\mathrm{t}$ testi uygulanmıştır.

\section{Bulgular}

Birleştirilmiş sınıflarda öğretim dersi kapsamında, birleştirilmiş sınıflı ilkokullardaki uygulamaların, sınıf öğretmenliği lisans programı dördüncü sınıf öğrencilerinin öğretmenlik tutumuna etkisinin incelendiği bu araştırmada, deneysel süreç sonunda sınıf öğretmenliği programı öğrencilerinin ögrtmenlik tutum ölçeğine vermiş olduğu cevapların frekans ve ortalamaları Tablo 1'de sunulmaktadır.

Tablo 1

\begin{tabular}{|c|c|c|}
\hline MADDELER & $f$ & $\bar{x}$ \\
\hline 1. Öğretmenliğin, manevi doyumu yüksek olan bir meslek olduğunu düşünüyorum. & 27 & 4,48 \\
\hline 2. Hiçbir zaman öğretmenlik yapmayı düşünmem. & 27 & 0,56 \\
\hline 3. Uzun dönemli tatil olanağı olsa da ögretmenlik yapmak istemem. & 27 & 0,32 \\
\hline 4. Öğretmen olma düşüncesi bile beni tedirgin eder. & 27 & 0,32 \\
\hline 5. Öğretmenliği çok seviyorum. & 27 & 4,56 \\
\hline 6. İşsiz kalsam da öğretmenlik yapmam. & 27 & 0,20 \\
\hline 7. Bence öğretmenlik sıkıcı bir meslektir. & 27 & 0,40 \\
\hline 8. Bütün zorluklarına rağmen, öğretmen olmayı tercih ederim. & 27 & 4,36 \\
\hline 9. Öğretmenliğin bana göre bir meslek olmadığını düşünüyorum. & 27 & 0,82 \\
\hline 10. Bütün gün başkalarının çocuklarıyla uğraşmanın hiç çekici olmadığını düşünüyorum. & 27 & 0,52 \\
\hline 11. İstediğim bir yerde olsa bile öğretmenlik yapmam. & 27 & 0,24 \\
\hline 12. Çocuklarla ve genç kuşakla bir arada olmanın kişiyi zinde ve canlı tuttuğuna inanıorum. & 27 & 4,52 \\
\hline 13. Parasal yönü iyileştirilse bile öğretmenlik yapmayı tercih etmem. & 27 & 0,36 \\
\hline 14. Öğretmenlik sözcüğ̈̈nü duymak bile beni huzursuz etmeye yetiyor. & 27 & 0,28 \\
\hline 15. Benim için en uygun mesleğin öğretmenlik olduğuna inanıyorum. & 27 & 4,28 \\
\hline 16. Hem çalıșıp hem kendime daha fazla vakit ayırabileceğim için öğretmenliği tercih ederim. & 27 & 3,76 \\
\hline 17. Kendimi, küçüklügüumden beri öğretmen olmak için hazırlıyorum. & 27 & 3,52 \\
\hline 18. Hayatta seçmeyi düşünebileceğim en son meslek öğretmenliktir. & 27 & 0,56 \\
\hline 19. Öğretmen olmak için yaratıldığıma inanıyorum. & 27 & 3,76 \\
\hline 20. Cocukları sevsem bile öğretmenlik yapmak istemem. & 27 & 0,52 \\
\hline 21. Öğretmenlik hayallerimi süsleyen bir meslektir. & 27 & 4,08 \\
\hline 22. Hangi koşullar altında olursa olsun, öğretmenlik yaparım. & 27 & 3,96 \\
\hline 23. Öğretmenlik yapmaktansa başka ișlerde çalışmayı tercih ederim. & 27 & 0,48 \\
\hline
\end{tabular}

Tablo 1 incelendiğinde, sınıf öğretmenliği lisans programı öğrencilerinin öğretmenliğe ilişkin tutumlarının yüksek seviyede olduğu görülmektedir. Meuniyetlerine çok kısa bir süre kalmış olan öğretmen adaylarının, öğretmenlik mesleğine olan tutumlarındaki bu yükseklik dikkat çekicidir. $\mathrm{Bu}$ sonuç olumlu ve istenilen bir durumdur. 
Birleștirilmiș sınıflarda öğretim dersi kapsamında, birleștirilmiș sınıflı ilkokullardaki uygulamaların, sınıf öğretmenliği lisans programı dördüncü sınıf öğrencilerinin öğretmenlik tutumuna etkisinin incelendiği bu araştırmada, öğretmenliğe ilişkin tutum ölçeği puanlarıyla ilişkili örneklemler için t testi sonuçları Tablo 2'de belirtilmektedir.

Tablo 2

Öğretmenliğe İlişkin Tutum Ölçeği Öntest ve Sontest Ortalama Puanların T-Testi Sonuçları

\begin{tabular}{lllllll}
\hline Ölçüm & $\mathrm{n}$ & $\bar{x}$ & $\mathrm{~S}$ & $\mathrm{sd}$ & $\mathrm{t}$ & $\mathrm{p}$ \\
\hline Öntest & 27 & 4,20 &, 66 & 26 & 1,48 &, 15 \\
Sontest & 27 & 4,37 &, 61 & 26 & \\
\hline
\end{tabular}

Tablo 2 incelendiğinde, öğretmenliğe ilişkin tutum ölçeği öntest puanları ortalamasının $\bar{x}=4,20$, öğretmenliğe ilişkin tutum ölçeği sontest puanları ortalamasının $\bar{x}=4,37$ olduğu görülmektedir. Öğretmenliğe ilişkin tutum ölçeği öntest puanları ile öğretmenliğe ilişkin tutum ölçeği sontest puanları arasında anlamlı bir farklılık olmadığı belirlenmiştir, $\mathrm{t}_{(26)}=1,48, \mathrm{p}>, 05$. Öğrencilerin öğretmenliğe ilişkin tutum ölçeği öntest puan ortalamaları $(\bar{x}=4,20)$ ve sontest puan ortalamaları $(\bar{x}=4,37)$ incelendiğinde, sınıf eğitimi anabilim dalı son sınıf öğrencilerinin öğretmenliğe ilişkin olumlu yüksek derecede tutum sahibi oldukları tespit edilmiştir. Öğretmenliğe ilişkin tutum ölçeği öntest puanları ile öğretmenliğe ilişkin tutum ölçeği sontest puanları arasında anlamlı bir fark olmamasına rağmen, öğretmenlik tutumunda az da olsa katkı sağladığı görülmektedir.

\section{Sonuç, Tartışma ve Öneriler}

Birleştirilmiş sınıflarda öğretim dersi kapsamında, birleştirilmiş sınıflı ilkokullarda uygulamaların, sınıf öğretmenliği programı dördüncü sınıf öğrencilerinin öğretmenlik tutumuna etkisinin incelendiği bu araştırmada öğretmenliğe ilişkin tutum ölçeği öntest puanları ortalaması $\bar{x}=4,20$, öğretmenliğe ilişkin tutum ölçeği sontest puanları ortalamas $\bar{x}=4,37$ olarak bulunmuştur. Öğretmenliğe ilişkin tutum ölçeği öntest puanları ile öğretmenliğe ilişkin tutum ölçeği sontest puanları arasında anlamlı bir farklılık olmadığ ölçeği öntest puan ortalamaları $(\bar{x}=4,20)$ ve sontest puan ortalamaları $(\bar{x}=4,37)$ incelendiğinde, sınıf eğitimi anabilim dalı son sınıf öğrencilerinin öğretmenliğe ilişkin olumlu yüksek derecede tutum sahibi oldukları tespit edilmiştir. Öğretmenliğe ilişkin tutum ölçeği öntest puanları ile öğretmenliğe ilişkin tutum ölçeği sontest puanları arasında anlamlı bir fark olmamasına rağmen, öğretmenlik tutumunda az da olsa katkı sağladığı ortaya çıkmıştır. Bulunan bu sonuca benzer bir şekilde, Sağ (2010) tarafindan yapılan araştırma sonucunda, birleştirilmiş sınıflardaki uygulamaların sınıf öğretmeni adaylarının özyeterliklerinde artışa neden olduğu ortaya konulmuştur. Konu ile ilgili olarak İzci (2008) tarafindan yapılan araştırma sonuçları önemlidir. Öğretmen adayları; birleştirilmiş sınıflar ile ilgili bilgi ve becerilerinin yeterli olmadığını belirtmişlerdir. Fakülte öğrenimi sürecinde görmüş oldukları birleştirilmiş sınıflarda öğretim dersinin mevcut haliyle bu alandaki bilgi ve becerilerinin belli bir düzeye ulaşmasına katkı sağlamayacağı ortaya konulmuştur. Mezuniyet sonrası birleştirilmiş sınıflarda göreve başladıklarında öğrencilere nasıl davranılacağını yeterince bilmedikleri vurgulanmıştır. Yükseköğretim Kurulu Başkanlığı (2006) sınıf öğretmenliği lisans programı ders tablosuna göre, birleştirilmiş sınıflarda öğretim dersi iki saat teorik bir derstir. Uygulaması yoktur. Yapılan bu araştırma ile sınıf öğretmenliği lisans programı öğrencilerine adı geçen ders kapsamında uygulama yaptırılmıştır. Uygulama sonucunda, lisans programı öğrencilerinin öğretmenlik tutumunda az da olsa katkı sağladığ ortaya çıkmıştır.

Araştırma bulguları kapsamında aşağıda belirtilen önerilerde bulunulmuştur:

- Birleştirilmişs sınıflarda öğretim dersi kapsamında, sınıf öğretmenliği programı öğrencilerinin mutlaka birleştirilmiş sınıflı ilkokullara götürülmesi gerekmektedir.

- Yükseköğretim Kurulu Başkanlığı tarafından, sınıf öğretmenliği lisans ders programı hazırlanırken birleştirilmiş sınıflarda öğretim dersi için bir saat uygulama saati eklenebilir.

- Yükseköğretim Kurulu Başkanlığı tarafından hazırlanan sınıf öğretmenliği lisans derslerine birleştirilmişs sınıflarda öğretim dersinin tekrar eklenmesi önerilmektedir. 
- Birleştirilmiş sınıflı ilkokullarda uygulamalar ardından, sınıf öğretmenliği programı öğrencileri ile nitel araştırmalar yapılabilir.

- Benzer çalışmalar, yatılı ilköğretim bölge okullarında yapılabilir.

- Benzer araştırmalar, birleştirilmiş sınıf öğretmenleri ve öğrencileri ile yapılabilir.

- Benzer araştırmalar sınıf öğretmenliği lisans programı öğrencilerinin özyeterlik algıları üzerine yapilabilir.

Açıklamalar: $\mathrm{Bu}$ araştırma, 08-11 Mayıs 2017 tarihlerinde Lefke Avrupa Üniversitesinde düzenlenen 16. Uluslararası Sınıf Öğretmenliği Eğitimi Sempozyumunda sunulmuş sözlü bildirinin geliştirilmiş halidir. Araştırmanın özeti sözlü bildiri olarak sunulmuş ancak tam metin olarak basılmamıştır. 


\section{Kaynaklar}

Birch, I. ve Lally, M. (1995), Multigrade teaching in primary schools. UNESCO Principal Regional Office for Asia and the Pacific.

Büyüköztürk, Ş. (2012), Sosyal bilimler için veri analizi el kitabı (17. Baskl). Ankara: Pegem Akademi.

Christensen, L. B., Johnson, R. B. ve Turner, L. A. (2015). Araştırma yöntemleri desen ve analiz (Çev. Edt: Ahmet Aypay). Ankara: Anı Yayıncılık.

Eker, C. ve Sıcak, A. (2016). Sınıf öğretmeni adaylarının birleştirilmiş sınıflı öğretime ilişkin zihin imgeleri (metaforları). Mehmet Akif Ersoy Üniversitesi Ĕ̈itim Fakültesi Dergisi, 6(37), 133 153.

Erdem, A. R. (2015). Birleştirilmiş sınıflarda öğretim (yeni programa göre gözden geçirilmiş 7. bask1). Ankara: An1 Yayıncilik.

Erkuş, A., Sanlı, N., Bağlı, M. T. ve Güven, K. (2000). Öğretmenliğe ilişkin tutum ölçeği geliştirilmesi. Eğitim ve Bilim, 25(116), 27-33.

Genç, S. Z. (2005). İlköğretim 1. kademedeki okul-aile işbirliği ile ilgili öğretmen ve veli görüşleri. Türk Eğitim Bilimleri Dergisi, 3(2), 227-243.

Glesne, C. (2012). Nitel araştırmaya giriş. (A. Ersoy ve P. Yalçınoğlu, Çev.). Ankara: Anı Yayıncılık.

Gliner, J. A., Morgan, G. A. ve Leech, N. L. (2015). Uygulamada araştırma yöntemleri: desen ve analizi bütünleştiren yaklaşım (Çev. Ed.: Selahattin Turan). Ankara: Nobel Yayın Dağıtım.

Gültekin, M. (2012). Birleştirilmiş sınıflar. İçinde Gültekin, M. (Ed.), Birleştirilmiş sınıflarda öğretim (ss. 1-22). Eskişehir: Anadolu Üniversitesi Açıköğretim Fakültesi.

Hargreaves, E., Montero, C., Chau, N., Sibli, M. ve Thanh, T. (2001).Multigrade teaching in peru, sri lanka and vietnam: an overview. International Journal of Educational Development, 21(6), 499-520.

İlter, İ. (2015). Sınıf öğretmeni adaylarının birleştirilmiş sınıf kavramına ilişkin metaforları. İlköğretim Online, 14(4), 1450-1468.

İnce, N. B. ve Șahin, A. E. (2016). Birleştirilmiş ve bağımsız sınıflarda çalışan sınıf öğretmenlerinin mesleki doyum ve tükenmişlik düzeylerinin karşılaştırılması. Hacettepe Üniversitesi Ĕgitim Fakültesi Dergisi, 31(2), 391-409.

İzci, E. (2008). İlköğretim bölümü sınıf öğretmenliği programı öğrencilerinin birleştirilmiş sınıflarda öğretime ilişkin görüşleri. Elektronik Sosyal Bilimler Dergisi, 7(25), 111-122.

İzci, E., Duran, H. ve Taşar, H. (2010). Birleştirilmiş sınıflarda öğretimin sınıf öğretmeni adaylarının algılarına göre ve birleştirilmiş sınıflarda görev yapan sınıf öğretmenlerinin görüşleri açısından incelenmesi. Kırşehir Ĕgitim Fakültesi Dergisi, 11(1), 19-35.

Karasar, N. (1994). Bilimsel Araştırma Yöntemi. 3A Araştırma Eğitim Danışmanlık Ltd., Ankara.

Kazu, H. ve Aslan, S. (2016). Sınıf öğretmeni adaylarının birleştirilmiş sınıf uygulamasına ilişkin görüşlerinin incelenmesi (fırat ve dicle üniversiteleri örnekleri). Uluslararası Türk Kültür Coğrafyasinda Sosyal Bilimler Dergisi, 1(2), 23-32.

Little, A. W. (2006). Education For All: Multigrade Realities And Histories. In Education for All and Multigrade Teaching (pp. 1-26). Netherlands: Springer.

MEB (Milli Eğitim Bakanlığı) (2012). Birleştirilmiş Sınıflar Uygulaması. https://tegm.meb.gov.tr/meb_iys_dosyalar/2012_10/11110255_birlestirilmis_snflar_haf_ders_ prg.pdf.

Merriam, S. B. (2013). Nitel araştırma desen ve uygulama için bir rehber (Çev. Ed.: Selahattin Turan). Ankara: Nobel Akademik Yayıncılık.

Mulryan-Kyne, C. (2007). The preparation of teachers for multigrade teaching. Teaching and Teacher Education, 23(4), 501-514.

Patton, M. Q. (2014). Nitel araştırma ve değerlendirme yöntemleri (3. Baskıdan Çeviri) (Çev. Edt: Mesut Bütün, Selçuk Beşir Demir). Ankara: Pegem Akademi. 
Sağ, R. (2010). Etkinlik teorisine göre zenginleştirilmiş birleştirilmiş sınıflarda öğretim uygulamalarının adayların özyeterlik algılarına etkisi. Ĕgitim ve Bilim, 35(158), 44-57.

Sağ, R. (2011). Birleştirilmiş Sınıf Öğretmeni Olmaya Yönelik Özyeterlik Ölçeği Geliştirilmesi. Hacettepe Üniversitesi Ĕ̈itim Fakültesi Dergisi, (41), 386-397.

Sağ, R., Savaş, B. ve Sezer, R. (2009). Burdur'daki birleştirilmiş sınıf öğretmenlerinin özellikleri, sorunları ve ihtiyaçları. İn̈nü Üniversitesi Eğitim Fakültesi Dergisi, 10(1), 37-56.

Taşdemir, M. (2014). Birleştirilmiş sınıflar hakkında sınıf öğretmeni adaylarının görüşleri: beklenti ve metaforlar. Turkish Studies, 9(2), 1459-1475.

Thomas, C. ve Shaw, C. (1963). Issues in the development of multigrade Schools (Vol. 172). Washington, DC: World Bank.

Yıldırım, A. ve Şimşek, H. (2006). Sosyal bilimlerde nitel araştırma yöntemleri (6. Baskı). Ankara: Seçkin Yayıncılık.

Yıldız, M. ve Köksal, K. (2009). Birleştirilmiş sınıf uygulamasına ilişkin öğretmen görüşlerinin değerlendirilmesi. Kastamonu Eğitim Dergisi, 17(1), 1-14.

Yükseköğretim Kurulu Başkanlığı (2006). Sınıf öğretmenliği lisans programı. http://www.yok.gov.tr/documents/10279/49665/sinif_ogretmenligi.pdf/32dd5579-2e4d-454e8c91-5e0594ebdf48. 


\section{Extended Abstract}

\section{Introduction}

The multigrade class is one of the realities of our country. Multigrade class is applied for reasons such as lack of number of students, insufficient number of teachers, insufficient number of classrooms or distribution of settlements. Although the multigrade class is seen as a disadvantage for the student, it is important for the students to take the compulsory primary school education.

The aim of this study is to investigate the effects of the applications in the multigrade class primary schools on the teaching attitude of the fourth year students of the classroom teacher program. It is a two-hour theoretical course in teaching classes in multigrade classes, according to the course schedule of the classroom teacher degree program. There is no application. In the classroom teaching program put into effect by the Board of Higher Education in 2018, there is no teaching class in the multigrade classrooms. With this research, the application dimension was added to the teaching class in the multigrade classes. This is important in terms of examining the effect of the application. It is thought that the results of the research will be beneficial to the commission that prepares teaching license programs at the Presidency of Higher Education Council. Besides, it is thought that it will give an idea to the researchers working in the field of multigrade class.

\section{Method}

This research, in which the effects of the applications in the primary schools of the multigrade classrooms on the teaching attitude of the students of the classroom teaching program are examined in one group pretest-posttest experimental design. The population of the study is composed of the fourth grade students studying in the Yozgat Bozok University Faculty of Education. The sample was not taken, the whole universe was reached. In order to determine the universe and the sample, easy-to-use sampling and criterion sampling were used. As a criterion, the students who took the teaching class in the multigrade classes were determined. There are 27 students in the multigrade classrooms. 8 of these students are male and 19 are female. The research was conducted in February and March 2017. In the scope of the research, a four-week period was applied in the unified class primary schools in Yozgat. In the spring semester of 2016-2017 academic year, experimental process was carried out with fourth grade students in the classroom teaching program that took the teaching class in the multigrade classes. Within the scope of the plan prepared by the researcher, lesson activities and practices were realized by the students in the multigrade classes. The researcher provided consultancy services to fourth grade students in the classroom teaching program in the experimental process. SPSS program was used for data analysis. The markings that students have stated in the lar1 Attitude towards Teaching Scale li were entered into the SPSS program. As a result of the Shapiro-Wilks test, $p=, 16$ were found. After determining the normal distribution of the data, t-test was applied for the related samples.

\section{Results}

The mean scores of the attitude scale pre-test scores were 4.20 and the post-test scores of the teacher attitude scale were found to be $\bar{x}=4.37$. There was no significant difference between the pre-test scores of the attitude scale and the post-test scores of the attitude scale related to teaching, $\mathrm{t}_{(26)}=1.48$, $\mathrm{p}>.05$. When the mean scores of the attitude scale $(\bar{x}=4.20)$ and posttest mean scores $(\bar{x}=4.37)$ of the students were examined, it was determined that the students of the senior education department had a positive attitude towards teaching. Although there is no significant difference between the attitude scale pre-test scores of the teaching attitude and the post-test scores of the attitude scale related to teaching, it seems that it contributes a little to the teaching attitude.

\section{Discussion and Conlusion}

Within the scope of the multigrade classrooms lesson, the effects of the practices in the multigrade class primary schools on the teaching attitude of the fourth grade students were examined in this study. There was no significant difference between the pre-test scores of the attitude scale and the post-test scores of the attitude scale related to teaching, $\mathrm{t}_{(26)}=1.48, \mathrm{p}>.05$. When the mean scores of the attitude scale $(\bar{x}=4.20)$ and posttest mean scores $(\bar{x}=4.37)$ of the students were examined, it was determined that the students of the senior education department had a positive attitude towards teaching. Although there was no significant difference between the pre-test scores of the attitude scale and the 
post-test scores of the teaching attitude, it was found that it contributed a little to the teaching attitude. Similarly to this conclusion, the results of the research conducted by Sağ (2010) showed that the applications in the multigrade classes lead to an increase in the self-efficacy of the teacher candidates. The results of the survey conducted by İzci (2008) are important. Teacher candidates; stated that their knowledge and skills about the multigrade classes were not sufficient. It has been revealed that the teaching classes in the multigrade classrooms they have seen during the faculty education process will not contribute to their level of knowledge and skills in this area to reach a certain level. It was emphasized that students did not know enough how to behave when they started working in postgraduation classrooms. Higher Education Council (2006) is a two-hour theoretical course in teaching classes in multigrade classes, according to the course schedule of the classroom teacher degree program. There is no application. With this study, the students of the classroom teaching program have been applied within the scope of the mentioned course. As a result of the application, it was revealed that undergraduate students contributed a little to their teaching attitude.

Within the scope of the research findings, the following recommendations were made:

- As part of the multigrade classroom teaching course, students of the classroom teaching program must be taken to primary schools with multigrade classrooms.

- The Board of Higher Education may add one hour of practice time for the teaching lesson in the multigrade classes during the preparation of the undergraduate program.

- It is recommended to add the teaching lesson again in the multigrade classrooms to the classroom teaching courses prepared by the Council of Higher Education.

- Qualitative research can be carried out with classroom teaching program students following the applications in primary schools.

- Similar studies can be done in regional boarding schools.

- Similar research can be done with multigrade classroom teachers and students.

- Similar research can be done on the perceptions of self-efficacy of the students in the undergraduate program. 